\title{
(2) OPEN ACCESS \\ Identification of work-related injury emergency department visits using International Classification of Diseases, Tenth Revision, Clinical Modification (ICD- 10-CM) codes
}

\author{
Ashley M Bush @ , Terry L Bunn 주, Madison Liford
}

- Additional material is published online only. To view please visit the journal online (http://dx.doi.org/10.1136/ injuryprev-2019-043507).

Kentucky Injury Prevention and Research Center, University of Kentucky, Lexington, Kentucky, USA

\section{Correspondence to}

Dr Ashley M Bush, Kentucky Injury Prevention and Research Center, University of Kentucky, Lexington, KY 40504, USA; ashleybush@uky.edu

Received 30 January 2020 Revised 19 November 2020 Accepted 27 November 2020
Check for updates

(C) Author(s) (or their employer(s)) 2021. Re-use permitted under CC BY-NC. No commercial re-use. See rights and permissions. Published by BMJ.

To cite: Bush AM, Bunn TL, Liford M. Inj Prev

2021:27:i3-i8.
ABSTRACT

Introduction Emergency department (ED) visit discharge data are a less explored population-based data source used to identify work-related injuries. When using discharge data, work-relatedness is often determined by the expected payer of workers' compensation (WC). In October 2015, healthcare discharge data coding systems transitioned to the International Classification of Diseases, Tenth Revision, Clinical Modification (ICD10-CM). ICD-10-CM's structure offers potential new work-related codes to enhance work-related injury surveillance. This study identified work-related ED visits using relevant ICD-10-CM work-related injury codes. Cases identified using this method were compared with those identified using the WC expected payer approach. Methods State ED visit discharge data (2016-2019) were analysed using the CDC's discharge data surveillance definition. Injuries were identified using a diagnosis code or an external cause-of-injury code in any field. Injuries were assessed by mechanism and expected payer. Literature searches and manual review of ICD-10CM codes were conducted to identify possible workrelated injury codes. Descriptive statistics were performed and assessed by expected payer.

Results WC was billed for 87361 injury ED visits from 2016 to 2019. Falls were the most frequent injury mechanism. The 246 ICD-10-CM work-related codes identified $36 \%$ more work-related ED injury visits than using WC as the expected payer alone.

Conclusion This study identified potential ICD-10-CM codes to expand occupational injury surveillance using discharge data beyond the traditional WC expected payer approach. Further studies are needed to validate the work-related injury codes and support the development of a work-related injury surveillance case definition.

\section{INTRODUCTION}

Research and epidemiological studies on occupational injuries in the USA rely heavily on the use of various secondary data sources. ${ }^{1}$ There is no single comprehensive data source of worker injuries, and traditional sources (eg, workers' compensation (WC) claims and Bureau of Labor Statistics reports) often underestimate the burden and scope of workrelated injuries because they capture only severe injuries, rely on self-reports and exclude certain work establishments (eg, small farms) and the selfemployed. $^{2-4}$ Statewide population-level hospital discharge data are also increasingly utilised in the prevention and control of occupational injuries. ${ }^{5}$

Despite not being designed for occupational injury surveillance, discharge data such as emergency department (ED) visits can potentially provide information on work-related injuries. With the ED visit data, work-relatedness is often determined by filtering by expected payer of WC, a suitable proxy for work-relatedness. ${ }^{5-9}$ The Council of State and Territorial Epidemiologists and researchers use WC payer as a proxy for occupational health indicators and work-related injuries requiring medical care. ${ }^{67910}$ However, this method underestimates work-related injuries, often only capturing more severe injuries-the portion requiring medical treatment. ${ }^{10}$ The National Hospital Ambulatory Medical Surveys, a nationally representative ED visit dataset, found $40 \%$ of work-related $\mathrm{ED}$ visits were paid by non-workers' compensation (nonWC) sources. ${ }^{10}$ To overcome the limitations of solely using WC as expected payer to identify workrelated injuries, several studies have explored using International Classification of Diseases, Ninth Revision, Clinical Modification (ICD-9-CM) external cause codes with discharge data to identify causes of workplace injuries. ${ }^{67}$

Healthcare and hospitals transitioned discharge data coding systems from ICD-9-CM to ICD Tenth Revision, Clinical Modification (ICD-10-CM) codes in October 2015, expanding coding specificity and structure. ${ }^{11-15}$ The coding transitioned from a primary axis of nature of injury (ICD-9-CM) to the primary axis of body region (ICD-10-CM), expanding to more than 43000 injury diagnosis codes in ICD-10-CM, compared with 2600 codes under ICD-9-CM. ${ }^{13}$ The external causes of morbidity that provide details on the injury mechanism (eg, fall, motor vehicle crash, drug poisoning), intention (unintentional, intentional or undetermined), place of occurrence, activity at time of injury (eg, dancing) and employment status (eg, military, civilian), increased from 1300 codes in ICD-9-CM to 7500 in ICD-10-CM. ${ }^{13}$ These codes are important for population-based injury surveillance; however, they are not required for discharge billing reimbursement. ${ }^{16}$ Other important coding structure changes that affect injury surveillance due to the transition are described elsewhere..$^{113-15} 17$

The new coding system enhanced the potential identification of work-related injuries through 
expansion of possible work-related ICD-10-CM codes. For example, traffic-related injury codes in ICD-9-CM provided limited information regarding the injury event (eg, E10.0, motor vehicle traffic collision with train injuring driver of motor vehicle other than motorcycle). The ICD-10-CM coding system allows for expanded detail regarding the traffic-related injury and circumstances (eg, V65.5, driver of heavy transport vehicle (tractor-trailer) injured in traffic collision with railway train or vehicle). The possible impact of the ICD-10-CM coding transition on the identification of work-related injuries remains mostly unexamined.

This study's objectives were to (1) examine work-related injuries by expected payer, (2) identify possible work-related injuries using ICD-10-CM codes through published literature and manual reviews and (3) assess the change in capture of workrelated injuries via the ICD-10-CM work-related injury codes compared with the traditional WC expected payer approach alone.

\section{METHODS \\ Study data}

Data for this study were obtained from the Kentucky outpatient services database in the Office of Health Data and Analytics at the Kentucky Cabinet for Health and Family Services. Records were deidentified per state data agreements and reflected ED encounters of care rather than unique numbers of individuals receiving care for an injury. Calendar year was based on date of discharge. Records were not limited by patient state of residence for better approximation of resident and non-resident workrelated injuries. This study was approved by the University of Kentucky Institutional Review Board. Analyses were conducted using SAS V.9.4 (SAS Institute Inc, Cary, North Carolina, USA).

\section{ICD-10-CM ED visit records}

Injury-related ED visits were identified from records with a discharge date of 1 January 2016, to 31 December 2019, guided by CDC's 2017 proposed surveillance case definition for injury ED visits. ${ }^{18}$ Only initial encounters were included (a seventh character of 'A' or missing) in the ED dataset using a diagnosis code of S00-S99, T07-T34, T36-T50 with a sixth character of 1, 2, 3 or 4; T36.9, T37.9, T39.9, T41.4, T42.7, T43.9, T45.9, T47.9 and T49.9 with a fifth character of $1,2,3$ or 4 ; T51-T65, T66-T76, T79; or an external cause-of-injury code of V00V99, W00-X58, X71-X83, X92-Y09, Y21-Y33 or Y35-Y38. ${ }^{18}$ Subsequent and sequelae visits were omitted.

The CDC ICD-10-CM external cause-of-injury matrix was used to categorise the injury visit by mechanism of injury. ${ }^{11}$ The completeness of cause-of-injury coding was $86.9 \%$. Injury mechanisms were filtered by expected payer. All ED visits had at least one payer listed; $78.8 \%$ had only one payer; $19.4 \%$ had two; and $1.9 \%$ had three. Expected payer was subdivided into two groups-WC payer and non-WC payer. When more than one expected payer was listed, an 'any mention' approach was used to classify visits as WC or non-WC payer. The distribution for WC as an expected payer was $98.1 \%$ using the first payer field (85 674 visits), 1.4\% using the second (1244 visits) and $0.5 \%$ using the third (443 visits).

To identify a subset of ICD-10-CM external causes of morbidity that might be work-related, two research team members (ML and AMB) manually assessed all possible ICD-10-CM external cause of morbidity codes for likelihood of being work-related. Each team member independently assessed the codes and then shared results. If there was disagreement, the third research
Table 1 ICD-10-CM ED injury visits*, injury mechanism by expected payer, Kentucky 2016-2019

\begin{tabular}{|c|c|c|c|}
\hline \multirow[b]{2}{*}{ Mechanism of injury $\dagger$} & \multirow[b]{2}{*}{$\begin{array}{l}\text { ED injury } \\
\text { visits }\end{array}$} & \multicolumn{2}{|c|}{ Expected payer } \\
\hline & & $\begin{array}{l}\text { WC } \\
(\%)\end{array}$ & $\begin{array}{l}\text { Non-WC } \\
(\%)\end{array}$ \\
\hline Cut/pierce & 132715 & $12263(9.4)$ & $120452(90.8)$ \\
\hline Drowning/submersion & 444 & $1(0.2)$ & $443(99.8)$ \\
\hline Fall & 616713 & $17878(2.9)$ & 598835 (97.1) \\
\hline Fire/burn & 22982 & $2116(9.2)$ & $20866(90.8)$ \\
\hline Firearm & 4654 & $43(0.9)$ & 4611 (99.1) \\
\hline Machinery & 11849 & $3492(29.5)$ & $8357(70.5)$ \\
\hline All transportation & 286098 & $6556(2.3)$ & $279542(97.7)$ \\
\hline Motor vehicle traffic crash & 232260 & $5293(2.3)$ & 226967 (97.7) \\
\hline Non-traffic & 21838 & $555(2.5)$ & $21283(97.5)$ \\
\hline Pedal cyclist & 8746 & $21(0.2)$ & 8725 (99.8) \\
\hline Pedestrian & 3152 & $170(5.4)$ & $2982(94.6)$ \\
\hline Other transport & 20102 & $517(2.6)$ & 19585 (97.4) \\
\hline Nature/environment & 94076 & $2302(2.5)$ & 91774 (97.6) \\
\hline Overexertion & 110015 & $8410(7.6)$ & 101605 (92.4) \\
\hline Poisoning & 62909 & 975 (1.5) & $61934(98.5)$ \\
\hline Drug-related & 52327 & $250(0.5)$ & 52077 (99.5) \\
\hline Non-drug-related & 10582 & $725(6.9)$ & 9857 (93.2) \\
\hline Struck by/against & 268673 & $16092(6.0)$ & $252581(94.0)$ \\
\hline Suffocation & 1535 & $6(0.4)$ & $1529(99.6)$ \\
\hline Other specified & 89334 & $5490(6.2)$ & 83844 (93.9) \\
\hline Unspecified & 168990 & $5685(3.4)$ & 163305 (96.6) \\
\hline Not elsewhere classified & 7215 & $264(3.7)$ & $6951(93.3)$ \\
\hline Undetermined mechanism $\ddagger$ & 182534 & $5788(3.2)$ & $176746(96.8)$ \\
\hline Total & 2060736 & $87361(4.2)$ & $1973375(95.8)$ \\
\hline
\end{tabular}

*ED visits represent encounters of care and could be greater than the number of individual patients treated.

†Mechanism of injury codes are cited elsewhere. ${ }^{11}$

‡Undetermined mechanism includes injury encounters without sufficient documentation to determine mechanism.

ED, emergency department; ICD-10-CM, International Classification of Diseases, Tenth Revision, Clinical Modification; WC, workers' compensation.

team member (TLB) weighed in on the work-related codes in question. External causes of morbidity for legal intervention (Y35), supplementary factors (Y90-Y98), external cause status (Y99) and other injury events that were likely work-related were included (online supplemental appendix A).

The completeness of coding among all injury visits $(n=2060$ 736) was $1.9 \%$ (39 281 visits: $59.0 \%$ WC, $41.0 \%$ non-WC) for a work-related employment status code, $0.2 \%$ (4305 visits: $7.7 \%$ WC, $92.3 \%$ non-WC) for a work-related activity code and $0.9 \%$ (19 131 visits: $48.5 \%$ WC, 51.5\% non-WC) for a work-related place of occurrence code. The coding completeness was 3.1\% for the entire $\mathrm{ED}$ visit discharge dataset having at least one workrelated code (63 459 visits: 50.5\% WC, $49.5 \%$ non-WC). Workrelated injuries identified by external causes of morbidity were not mutually exclusive.

\section{RESULTS}

Based on ICD-10-CM case selection criteria, there were 2060 736 injury visits treated in Kentucky ED facilities from 2016 to 2019. WC was included as an expected payer for 87361 visits (4.2\%, table 1$)$. Falls were the most frequent injury mechanism $(29.9 \%)$. The mechanism with the highest proportion of injury ED visits with an expected payer of WC was machinery (29.5\%). Among injury ED visits with $\mathrm{WC}$ as the expected payer, the most common mechanisms were fall (20.5\%), struck by/against (18.4\%) and cut/pierce (14.0\%) injuries.

The research team identified 246 ICD-10-CM codes as possibly work-related (online supplemental appendix A); the 
Table 2 ICD-10-CM ED injury visits* with work-related external cause of morbidity codes, by expected payer, Kentucky 2016-2019

\begin{tabular}{|c|c|c|c|}
\hline \multirow[b]{2}{*}{ External cause of morbidity code groups $t$} & \multirow[b]{2}{*}{ ED injury visits } & \multicolumn{2}{|c|}{ Expected payer } \\
\hline & & $\begin{array}{l}\text { WC } \\
(\%)\end{array}$ & $\begin{array}{l}\text { Non-WC } \\
(\%)\end{array}$ \\
\hline Transportation & 1940 & $711(36.7)$ & $1229(63.4)$ \\
\hline Driver of heavy transport vehicle injured in transport injury & 1026 & $416(40.6)$ & $610(59.5)$ \\
\hline Bus driver injured in transport injury & 290 & $91(31.4)$ & 199 (68.6) \\
\hline Other land transport injury & 625 & $204(32.6)$ & $421(67.4)$ \\
\hline Water transportation injury & 0 & $0(\mathrm{~N} / \mathrm{A})$ & $0(\mathrm{~N} / \mathrm{A})$ \\
\hline Air and space transport injury & 0 & $0(\mathrm{~N} / \mathrm{A})$ & $0(\mathrm{~N} / \mathrm{A})$ \\
\hline Exposure to force & 2644 & $740(28.0)$ & $1904(72.0)$ \\
\hline Fall from scaffolding & 310 & $73(23.6)$ & $237(76.5)$ \\
\hline Exposure to inanimate mechanical forces & 1823 & $509(27.9)$ & $1314(72.1)$ \\
\hline $\begin{array}{l}\text { Exposure to electric current, radiation, and extreme ambient air temperature and } \\
\text { pressure }\end{array}$ & 472 & $147(31.1)$ & $325(68.9)$ \\
\hline Other and unspecified effects and factors $\ddagger$ & 39 & $11(28.2)$ & $28(71.8)$ \\
\hline Legal intervention, war and military operations & 570 & $305(53.5)$ & $265(46.5)$ \\
\hline Place of occurrence & 19131 & $9278(48.5)$ & $9853(51.5)$ \\
\hline Industrial premise & 17026 & $9086(53.4)$ & $7940(46.6)$ \\
\hline Farm or slaughterhouse & 2105 & $192(9.1)$ & $1913(90.9)$ \\
\hline Military base or training grounds & 238 & $16(6.7)$ & $222(93.3)$ \\
\hline Activity & 4305 & $333(7.7)$ & $3972(92.3)$ \\
\hline Animal care, shearing, milking & 98 & $9(9.2)$ & $89(90.9)$ \\
\hline Building and grounds care & 4184 & $324(7.7)$ & $3860(92.3)$ \\
\hline Other, refereeing & 23 & $0(0.0)$ & $23(100.0)$ \\
\hline Employment status & 39281 & $23162(59.0)$ & $16119(41.0)$ \\
\hline Civilian activity done for income or pay & 39098 & $23146(59.2)$ & $15952(40.8)$ \\
\hline Military activity & 183 & $16(8.7)$ & $167(91.3)$ \\
\hline Any work-related external cause code & 63459 & $32024(50.5)$ & $31435(49.5)$ \\
\hline No work-related external cause code & 1997277 & $55337(2.8)$ & 1941940 (97.3) \\
\hline Total & 2060736 & $87361(4.2)$ & $1973375(95.8)$ \\
\hline
\end{tabular}

*ED visits represent encounters of care and could be greater than the number of individual patients treated.

†A visit may have multiple external cause of morbidity codes; a full list of these possible work-related codes can be found in online supplemental appendix A.

$\ddagger$ Other and unspecified effects and factors include other and unspecified effects of external causes, contact with heat and hot substances, and exposure to other specified factors.

ED, emergency department; WC, workers' compensation.

majority related to legal intervention, operations of war, military operations and terrorism (50.0\%) and transportation (37.0\%).

ICD-10-CM codes identified 63459 work-related ED injury visits regardless of expected payer (table 2). Among ED injury visits with a work-related code, regardless of expected payer, employment status (61.9\%) and place of occurrence (30.1\%) identified most of the work-related injuries. Of these, the most reported employment status and place of occurrence codes were civilian employment status (civilian activity done for income or pay, 61.6\%) and injuries on an industrial premise (26.8\%).

Over a third (36.7\%) of ED visits with WC as expected payer had a work-related external cause code (32 024 visits). Civilian employment status (72.3\%) was the most common work-related code observed among WC expected payer ED visits having any work-related code $(n=32024)$. ED visits with a work-related code indicating civilian employment status (59.2\%) and legal intervention, war and military operations $(53.5 \%)$ had the highest proportion of visits with WC as the expected payer.

Almost half $(49.5 \%)$ of the injury ED visits with any ICD-10-CM work-related external cause code had non-WC as the expected payer. Civilian employment status was the most common (50.7\%) work-related code observed among ED visits with non-WC as expected payer and any work-related code $(n=31435)$. ED visits with a work-related code indicating refereeing activity (100\%) and place of occurrence at a military base or training grounds (93.3\%) had the highest proportion of visits with non-WC as the expected payer.

ICD-10-CM work-related external causes of morbidity captured $36.0 \%$ more work-related injury visits than using WC expected payer alone (118 796 visits and 87 361, respectively, table 3).

\section{DISCUSSION}

This study assessed the combination of the traditional WC expected payer and external cause of morbidity codes in the ICD-10-CM coding system to identify work-related injuries. WC was the expected payer at a similar proportion in ICD-9-CM data (data not shown) and in other published studies. ${ }^{19}$ Falls were the most frequent injury mechanism among all ED visits (not just those that were work-related), including those with expected WC coverage, a finding consistent with other studies of work-related ED visits. ${ }^{2021}$ Contact with machinery injuries had the highest proportion of expected WC coverage, similar to other studies. ${ }^{6} 192022$

Only $8 \%$ of the injury ED visits with expected WC coverage were due to overexertion, under-representing the burden of work-related overexertion injuries requiring emergency care, as 
Table 3 ICD-10-CM work-related ED injury visits* by source of identification, WC or external cause of morbidity code, 2016-2019

\begin{tabular}{|c|c|c|c|c|}
\hline Discharge data coding system & $\begin{array}{l}\text { Visits identified using } \\
\text { expected payer of WC }\end{array}$ & $\begin{array}{l}\text { Visits identified by presence of } \\
\text { work-related codes among visits with } \\
\text { expected payer of non-WC }\end{array}$ & $\begin{array}{l}\text { All work-related ED } \\
\text { visits (either criteria) }\end{array}$ & $\begin{array}{l}\text { Percent increaset in } \\
\text { identification of work- } \\
\text { related ED visits }\end{array}$ \\
\hline ICD-10-CM & 87361 & 31435 & 118796 & 36.0 \\
\hline
\end{tabular}

*ED visits represent encounters of care and could be greater than the number of individual patients treated.

tPercent increase is the difference in the number of work-related visits identified when using WC payer versus non-WC and a work-related external cause code.

ED, emergency department; ICD-10-CM, International Classification of Diseases, Tenth Revision, Clinical Modification; WC, workers' compensation.

there were no overexertion injury mechanism codes in the first year of ICD-10-CM implementation. ${ }^{11}$ The first ICD-10-CM overexertion code (X50) went into effect in late 2016, with additional ICD-10-CM overexertion codes (X50.0, X50.1, X50.3 and X50.9) being added in $2019 .{ }^{11}$ As a result, actual overexertion injury-related ED visits were quantified by other injury mechanisms, resulting in undercounting.

This study identified 246 ICD-10-CM external cause of morbidity codes to characterise work-related injuries requiring emergency care or treatment. The majority of the work-related codes pertained to legal intervention and enhanced transportation. ICD-10-CM legal intervention codes specify the injured individual and injury mechanism, such as a law enforcement official injured during a legal intervention involving manhandling (Y35.811), an opportunity not previously offered under ICD-9-CM. ${ }^{23}$ The work-related transportation codes (eg, driver of heavy transport vehicle injured in collision with pedestrian or animal (V61.0)) offer an occupational epidemiology tool to identify high-risk worker populations and exposures and inform occupational injury prevention opportunities (eg, collaborations with Federal Motor Carrier Safety Administration and Offices of Highway Safety on a truck driver sharing-the-road campaign).

The incorporation of external causes of morbidity allowed for enhanced identification of work-related visits. The majority of injury ED visits with work-related codes were identified by the civilian employment status and place of occurrence codes, increasing the identification of work-relatedness compared with WC expected payer alone. Fifty-one percent of non-WC visits with a work-related code were identified via a civilian employment status. Moreover, the majority of injury ED visits noting military employment status had an expected payer of non-WC, suggesting WC alone is not optimum in identifying military work-related injuries. Injuries occurring on military bases were most often identified among ED injury visits with non-WC expected coverage.

Utilising multiple external causes of morbidity to assess work-related injuries may inform injury prevention planning programmes as well as workplace safety standards and regulations. This could prove particularly useful in identifying injuries among workers not typically covered by WC (eg, self-employed, contractors and temporary workers). For example, one in two legal intervention injuries had WC coverage, suggesting that not all law enforcement personnel are covered under WC insurance. This is expected, as law enforcement may not be employed directly by state and local government but contracted as civilian employees without employer-sponsored health insurance coverage. Utilising ICD-10-CM codes indicating injury to a law enforcement official in conjunction with the civilian employment status code may offer further insight and clarification. Additionally, activity codes, such as injuries while refereeing, bring awareness to injuries in an understudied worker population. No refereeing injuries were covered by WC, a finding consistent with their independent contractor status.
Few studies have used ED data to examine work-related injuries $^{19-21}$; most utilise hospitalisation data with the WC payer and some external cause codes. ${ }^{68}$ This study is among the first to demonstrate the utility of external causes of morbidity in identifying possible work-related injuries. Our results show that combining WC charged injury visits with respective ICD-10-CM external cause of morbidity codes enhanced the capture of workrelated ED visits by $36.0 \%$ over the use of WC expected payer alone. Future studies are needed to estimate the positive predictive value of these codes to capture work-related injuries treated in EDs, especially as WC expected payer is a good indicator of work-relatedness and just over one-third of expected WC injury visits had a possible work-related code. ${ }^{5-9}$

The inclusion of ICD-10-CM non-external cause of morbidity codes Z04.2 (encounter for examination and observation following work accident) and Z57 (occupational exposure to risk factors) warrant further consideration; this study assessed external cause of morbidity codes only. Utilisation of $Z$ codes may provide the reasoning for seeking ED treatment. Examination of $\mathrm{Z}$ codes allowed for the identification of possible workrelated injury ED visits that would not have been identified by WC expected payer or a work-related external cause code. Specifically, $30 \%$ of the 91 visits with a Z04.2 code and $22 \%$ of the 176 visits with a Z57 code were not identified by WC expected payer or a work-related code.

As most of the work-related ED visits in this study were identified by the use of employment status and place of occurrence codes, it is important to note that these external cause of morbidity codes are not required for reimbursement by Centers for Medicare and Medicaid Services or Kentucky statutes; ICD-10-CM coding mandates vary by state. The usefulness of external cause of morbidity codes is limited by the documentation of occupational information by healthcare practitioners. A sample of medical records from 12 EDs in one state reported 98\% ICD-9-CM completion and cause of injury accuracy was $65 \%$ and $57 \%$ for work-related and non-work-related cases, respectively; only $30 \%$ of all cases had completed place of occurrence codes ${ }^{22}$; medical record reviews are yet to be performed on work-related ICD-10-CM cases. Clinicians are encouraged to document adequate injury details (eg, mechanism, intent, location and preceding activity) in the medical record for accurate ICD-10-CM coding of the ED encounter by medical coders. The Council of State and Territorial Epidemiologists is encouraged to work with medical and professional associations to develop and deliver continuing education and training to raise awareness about the important role that health practitioners serve in work-related injury surveillance and prevention. Suggested training topics range from injury documentation and data entry to quality and completeness of population-based surveillance. Healthcare providers are integral for the accurate assignment by medical coders of ICD-10-CM work-related injuries seen in the ED. 
Assessing work-related injuries through the use of the primary WC payer field alone suggests an undercount of work-related ED visits. ${ }^{24}$ This study utilised all three available expected payer fields to identify work-related injuries and examined expected payer using a WC 'any mention' approach to expand accurate identification of work-related injury ED visits. The any mention of WC approach allowed $2 \%$ more work-related injuries to be identified. Follow-up studies on actual payment are needed.

Employing a combined WC expected payer and workrelated code approach in this study provided expanded identification of possible work-related injuries treated in the ED. With expanded ICD-10-CM codes now available in the ED visit dataset, the ED visit dataset should be an integral data source that supplements employer reports (eg, WC claims, Bureau of Labor Statistic reports) in worker injury surveillance. As alternative contractor relationships that do not provide WC coverage are increasing, ${ }^{25}$ quantifying workrelated injuries through supplemental data sources, such as ED data, is of utmost importance for accurate occupational injury surveillance. The expanded ICD-10-CM work-related external cause codes enhance occupational injury surveillance of non-traditional workers, such as migrant, self-employed, farm, temporary and uninsured workers.

\section{LIMITATIONS}

This study reports only on work-related injuries, not workrelated illnesses. Future work should assess the potential utility of ICD-10-CM codes to capture work-related illnesses, such as silicosis, in ED discharge data. ${ }^{26}$ Another limitation is that the data in this study represent the number of ED visits as opposed to individual injuries. Our state data policies require discharge data to be deidentified. As work-related injury visits presented in this study may have multiple external cause codes, work-related injury visits in this study are subject to potential misclassification and under-reporting or over-reporting, as the two approaches are not mutually exclusive. Studies are warranted to confirm the sensitivity and specificity of the

\section{What is already known on this subject?}

- Workers' compensation (WC) claims and labour statistics surveys are frequently used to identify worker injuries, but often underestimate the work-related injury burden. Work-related injuries are not exclusively captured by one data source. Previous research examining discharge data (emergency department (ED) visits) have often identified work-related injuries using the WC expected payer approach. Data coded using the International Classification of Diseases, Tenth Revision, Clinical Modification (ICD-10-CM) coding system has been less explored for occupational injury surveillance.

\section{What this study adds?}

- The WC expected payer approach in combination with work-related codes expand the utility of discharge data for population-based occupational injury surveillance. This study identifies 246 potential work-related ICD-10-CM codes. Use of these codes provides an opportunity to identify and assess worker injuries not covered by WC. external cause of morbidity codes in identifying work-related injuries. This study uses secondary data, utilising ICD coding systems designed for healthcare billing reimbursements. External causes of morbidity are not required for ED discharge purposes, and, as a result, completion may vary across facilities and jurisdictions. ${ }^{16}$ Future studies should assess the quality and completeness of work-related ICD-10-CM external cause of morbidity codes.

\section{Conclusion}

The work-related ICD-10-CM codes identified in this study allow for enhanced surveillance of occupational injuries not captured using only WC as the expected payer. As hospitals and healthcare facilities adopted ICD coding for discharge purposes and not injury surveillance purposes, work-related injuries can be better identified using the combined expected payer and external cause code approach based on the results of this study. The unique structure of ICD-10-CM permits the addition of more external cause codes in the future to enhance identification of work-related injuries in population-based discharge datasets.

Acknowledgements The authors would like to thank the Kentucky Cabinet for Health and Family Services, Office of Health Data and Analytics, for the provision of the statewide ED visit data. The authors additionally would like to thank the guest editors and reviewers for their critical insight to the further development of this manuscript.

Contributors All authors made substantial contributions from study conception to final version. Conception and general study design was done by AMB, TLB and ML. Methods development and refinement was performed by AMB and ML. Data acquisition, statistical analysis and data interpretation were done by AMB, TLB and ML. Manuscript drafting was done by AMB. Revisions were done by AMB, TLB and ML. Coauthor and peer review processes were performed by AMB. All authors provided final approval of the version to be published.

Funding This journal article was supported by Cooperative Agreement Number 6 U60OH008483-15-03, funded by the Centers for Disease Control and Prevention. Its contents are solely the responsibility of the authors and do not necessarily represent the official views of the Centers for Disease Control and Prevention or the Department of Health and Human Services.

Disclaimer The contents of this publication are solely the responsibility of the authors and do not necessarily represent the official views of the CDC in the United States Department of Health and Human Services, the State of Colorado, the State of Kentucky, the State of Maryland or the State of Massachusetts.

Competing interests None declared.

Patient consent for publication Not required.

Ethics approval This study is part of the broad spectrum of the Kentucky Occupational Safety and Health Surveillance program and is approved by the University of Kentucky Institutional Review Board.

Provenance and peer review Commissioned; externally peer reviewed.

Data availability statement The authorised secondary data sources were provided to the Kentucky Injury Prevention and Research Center, which is a representative and bona fide agent of the Kentucky Department for Public Health by Kentucky Cabinet for Health and Family Services, Office of Health Data and Analytics.

Supplemental material This content has been supplied by the author(s). It has not been vetted by BMJ Publishing Group Limited (BMJ) and may not have been peer-reviewed. Any opinions or recommendations discussed are solely those of the author(s) and are not endorsed by BMJ. BMJ disclaims all liability and responsibility arising from any reliance placed on the content. Where the content includes any translated material, BMJ does not warrant the accuracy and reliability of the translations (including but not limited to local regulations, clinical guidelines, terminology, drug names and drug dosages), and is not responsible for any error and/or omissions arising from translation and adaptation or otherwise

Open access This is an open access article distributed in accordance with the Creative Commons Attribution Non Commercial (CC BY-NC 4.0) license, which permits others to distribute, remix, adapt, build upon this work non-commercially, and license their derivative works on different terms, provided the original work is 
properly cited, appropriate credit is given, any changes made indicated, and the use is non-commercial. See: http://creativecommons.org/licenses/by-nc/4.0/.

\section{ORCID iDs}

Ashley M Bush http://orcid.org/0000-0001-8997-1839

Terry L Bunn http://orcid.org/0000-0002-5948-3313

\section{REFERENCES}

1 Azaroff LS, Levenstein C, Wegman DH. Occupational injury and illness surveillance: conceptual filters explain underreporting. Am J Public Health 2002;92:1421-9.

2 Rosenman KD, Kalush A, Reilly MJ, et al. How much work-related injury and illness is missed by the current national surveillance system? J Occup Environ Med 2006;48:357-65.

3 Souza K, Steege AL, Baron SL. Surveillance of occupational health disparities: challenges and opportunities. Am J Ind Med 2010;53:84-94.

4 Spieler EA, Burton JF. The lack of correspondence between work-related disability and receipt of workers' compensation benefits. Am J Ind Med 2012;55:487-505.

5 Thomsen C, McClain J, Rosenman K, et al. Indicators for occupational health surveillance. Mmwr Morb Mortal Wkly Rep 2007;56:1-6.

6 Alamgir $\mathrm{H}$, Koehoorn M, Ostry A, et al. An evaluation of hospital discharge records as a tool for serious work related injury surveillance. Occup Environ Med 2006;63:290-6.

7 Hunt PR, Won JU, Dembe A, et al. Work-Related hospitalizations in Massachusetts: racial/ethnic differences. Mon Labor Rev 2005;10:56-62.

8 Koehoorn M, Tamburic L, Xu F, et al. Characteristics of work-related fatal and hospitalised injuries not captured in workers' compensation data. Occup Environ Med 2015:72:413-20. doi:10.1136/oemed-2014-102543

9 Council of State and Territorial Epidemiologists (CSTE). Occupational health indicators, 2016. Available: https://www.cste.org/page/OHIndicators [Accessed 25 Nov 2019].

10 Groenewold MR, Baron SL. The proportion of work-related emergency department visits not expected to be paid by workers' compensation: implications for occupational health surveillance, research, policy, and health equity. Health Serv Res 2013;48:1939-59.

11 Hedegaard H, Johnson RL, Garnett MF, et al. The International classification of diseases, 10th revision, clinical modification (ICD-10-CM) external cause-of-injury framework for categorizing mechanism and intent of injury. Natl Health Stat Report 2019;136:1-22.

12 Safe States Alliance Injury Surveillance Workgroup 9 (ISW9). The transition from ICD9-CM to ICD-10-CM: guidance for analysis and reporting of injuries, 2016. Available: https://safestates.site-ym.com/?ISW [Accessed 12 Dec 2018].
13 Hedegaard H, Johnson RL, Warner M, et al. Proposed framework for presenting injury data using the International classification of diseases, tenth revision, clinical modification (ICD-10-CM) diagnosis codes. Natl Health Stat Report 2016;89:1-20.

14 National Center for Health Statistics. International classification of diseases (ICD10-CM/PCS) transition: impact on public health. centers for disease control and prevention, 2015. Available: https://www.cdc.gov/nchs/icd/icd10cm_pcs_impact.htm [Accessed 12 Nov 2019].

15 Annest JL, Hedegaard H, Chen L, et al. Proposed framework for presenting injury data using ICD-10-CM external cause of injury codes. centers for disease control and prevention, 2014. Available: http://www.cdc.gov/injury/wisqars/pdf//CD-10-CM_ External_Cause_Injury_Codes-a.pdf [Accessed 7 Dec 2019].

16 Slavova $\bar{S}$, Costich JF, Luu H, et al. Interrupted time series design to evaluate the effect of the ICD-9-CM to ICD-10-CM coding transition on injury hospitalization trends. Inj Epidemiol 2018;5:36.

17 Injury Surveillance Group. Consensus recommendations for using hospital discharge data for injury surveillance. Marietta (GA): state and territorial injury prevention directors association, 2003. Available: https://www.safestates.org/page//SWReports [Accessed 14 Nov 2019].

18 Hedegaard HB, Johnson RL, Ballesteros MF. Proposed ICD-10-CM surveillance case definitions for injury hospitalizations and emergency department visits. Natl Health Stat Report 2017;100:1-8.

19 Won J, Hunt PR, Davis L, et al. Emergency department visits for work-related injuries and illnesses in Massachusetts, 2001-2002: Massachusetts state department of public health, 2007. Available: https://www.mass.gov/files/documents/2016/07/vw/ work-related-emergency-visits-01-02.pdf [Accessed 9 Jan 2020].

20 Harduar Morano L, Richardson D, Proescholdbell S. Descriptive evaluation of methods for identifying work-related emergency department injury visits. Am J Ind Med 2019;62:568-79.

21 Tadros A, Sharon M, Chill N, et al. Emergency department visits for work-related injuries. Am J Emerg Med 2018;36:1455-8.

22 Hunt PR, Hackman H, Berenholz G, et al. Completeness and accuracy of international classification of disease (ICD) external cause of injury codes in emergency department electronic data. Inj Prev 2007;13:422-5.

23 Tiesman HM, Gwilliam M, Konda S, et al. Nonfatal injuries to law enforcement officers: a rise in assaults. Am J Prev Med 2018:54:503-9.

24 Sears JM, Bowman SM, Hogg-Johnson S. Disparities in occupational injury hospitalization rates in five states (2003-2009). AJIM 2015;58:528-40.

25 Katz LF, Krueger $A B$. The rise and nature of alternative work arrangements in the United States, 1995-2015. ILR Review 2019:72:382-416.

26 Dang GTT, Barros N, Higgins SA, et al. Descriptive review of asbestosis and silicosis hospitalization trends in North Carolina, 2002-2011. N C Med J 2013;74:368-75. 